\title{
OS DESAFIOS DAS AÇÕES SUSTENTÁVEIS NA INDÚSTRIA MADEIREIRA: O CASO DA SPS TECNOLOGIA AMBIENTAL LTDA
}

\author{
THE CHALLENGES OF SUSTAINABLE SHARES IN THE WOOD INDUSTRY: THE \\ CASE OF SPS TECNOLOGIA AMBIENTAL LTDA
}
Marcos Cieslak¹, Rosiane Mikuska², Alisson Sidney Dal Santos ${ }^{3}$, Carlos Alberto Marçal Gonzaga ${ }^{4}$

1 Unicentro/PPGDC, marcos_cieslak@yahoo.com.br

2 Unicentro /PPGDC, rosianemikuska@hotmail.com

3 Unicentro/PPGDC, alisson.sidney@hotmail.com

4 Unicentro/PPGDC, gonzaga@unicentro.br

ART ICLE IN F O

Article history:

Received 2019-06-17

Accepted 2020-01-03

Available online 2020-02-20
Palavras-chave: Desenvolvimento Sustentável. Resíduos. Indústria Madeireira.

Keywords: Sustainable Development. Waste. Lumber Industry.

RESUMO: O presente artigo é o resultado de um levantamento bibliográfico sobre o desenvolvimento sustentável, objetivando também comprovar a prática de boas intenções relacionadas com a sustentabilidade do setor madeireiro, aliando experiência, demanda local e conhecimento técnico para desenvolver novos produtos a partir da reutilização de resíduos industriais reativados, proporcionando resultados satisfatórios no que tange a aspectos ambientais e também econômicos. A presente pesquisa caracteriza-se como exploratória e estudo de caso, com entrevistas estruturadas com os principais atores. Entre as conclusões, aponta-se que o pré-conceito, o imediatismo e as falhas nas políticas ambientais são os principais desafios enfrentados por uma organização, a qual vem criando em paralelo uma nova linha de produtos na intenção de aproveitar sua atual estrutura.

ABSTRACT: This article is the result of a bibliographical survey on sustainable development. The objective of this study is to prove the practice of good intentions related to the sustainability of the timber sector, combining experience, local demand and technical knowledge to develop new products from the reuse of reactivated industrial waste, providing satisfactory results regarding the environmental aspects and also economical. The present research is characterized as exploratory and case study, with structured interviews with the main actors. Among the conclusions, it is pointed out that the preconception, the immediatism and the failures in environmental policies are the main challenges faced by this organization, which has been creating in parallel a new product line in order to take advantage of its current structure. 


\section{Introdução}

Partindo da premissa de que o nosso país tem vocação florestal não apenas para assegurar os mínimos padrões de qualidade de vida humana, fauna e flora, tal característica favorece o desenvolvimento de diversas atividades empresariais, entre elas o setor madeireiro, pois estamos no topo dos maiores países com áreas de florestas no planeta, perdendo apenas para a Rússia (851 milhões de ha). Em seguida está o Brasil (544 milhões de ha) e na sequência o Canadá (245 milhões de ha) (FAO, 2003).

Por um lado, nos estudos sobre sustentabilidade, um conceito bastante difundido é que o homem tem o direito fundamental à liberdade, à igualdade e ao desfrute de condições de vida adequadas em um meio ambiente de qualidade, tal que lhe permita levar uma vida digna e gozar de bem-estar, tendo a solene obrigação de proteger e melhorar o meio ambiente para as gerações presentes e futuras (CNUMAH, 1972).

Por outro, é de conhecimento geral, que nas últimas décadas imensas áreas de florestas foram devastas para dar lugar às plantações, pastagens, estradas e áreas urbanas. Sendo que cada vez mais é compreendido que as ações humanas têm fortes relações com as mudanças climáticas, proporcionando aumento de temperaturas, inundações, falta d'água e poluição do ar. Por isso, faz-se necessário a adoção de medidas sustentáveis e a preservação do meio ambiente, no que se refere também à exploração das florestas brasileiras e mundiais.

Uma das principais medidas apontadas por estudiosos está relacionada à mudança nos padrões de consumo e produção, os quais vêm afetando drasticamente a renovação dos recursos naturais, ou mesmo causando contaminações neles. Contudo, não há como negar a necessidade e a existência de um grande ciclo de extração da madeira desde longos períodos históricos, tendo na atualidade um significativo impacto socioeconômico, tanto nas comunidades presentes nos arredores de florestas, em atividades formais e informais, quanto na logística e na manufatura de produtos madeireiros, os quais também são importantes fornecedores de itens para construção civil e exportações, possuindo um significativo peso no PIB nacional.

Neste sentido, o presente artigo vem discutir e apresentar o resultado de um breve levantamento bibliográfico sobre o desenvolvimento sustentável, associado ao um caso prático de soluções ambientais realmente eficientes, porém esse exemplo ainda enfrenta desafios para sua plena consolidação. O caso utilizado consiste basicamente na reutilização de resíduos industriais provenientes da manufatura de portas e chapas compensadas de madeira, atividade tradicionalmente exercida nas Regiões Sul do Paraná e Norte Catarinense. 
O objetivo desse estudo não é demonstrar as fórmulas e processos desenvolvidos, mas sim comprovar as boas intenções e evidências práticas de sucesso, onde uma família de empreendedores preocupados com a sustentabilidade do setor madeireiro vem utilizando conhecimentos técnicos e sua larga experiência, aliados às demandas locais, desenvolvendo assim novos produtos a partir da reutilização de resíduos industriais reativados, proporcionando resultados satisfatórios no que tange a aspectos ambientais e também econômicos. Entretanto, ainda enfrentam dilemas de ordem cultural para expandir suas atividades, criando em paralelo uma nova linha de produtos na intenção de aproveitar sua estrutura existente.

\section{Fundamentação teórica}

\subsection{Visão objetiva da sustentabilidade}

Essencialmente a sustentabilidade visa buscar uma relação de equilíbrio entre o uso dos recursos naturais e as necessidades humanas, o que vem se tornando um desafio cada vez maior na atualidade. No entanto, a principal causa da degradação está associada ao consumo exacerbado dos segmentos afluentes das sociedades (BARBIERI, 2010). Por outro lado, famílias pobres, para atenderem suas necessidades a curto prazo, arruínam o capital natural, cortando mais árvores do que conseguem repor (WORLD BANK, 1992). E também é perceptível que problemas político-sociais têm interferência direta com a sustentabilidade.

Assim o termo está cada vez mais presente no ambiente empresarial, sendo que a definição mais difundida é a da Comissão Brundtland (1987), a qual considera que o desenvolvimento sustentável deve satisfazer as necessidades da geração presente sem comprometer as necessidades das gerações futuras. Essa definição deixa claro um dos princípios básicos da sustentabilidade, a visão de longo prazo.

Ademais, é fundamental entender os diversos aspectos da sustentabilidade, pois a mesma tem como princípio assegurar que as ações de hoje não limitarão a gama de opções econômicas, sociais e ambientais disponíveis para as futuras gerações (ELKINGTON, 1999). Podendo também destacar que uma organização e/ou empresa sustentável "é a que cria lucro para os seus acionistas enquanto protege o meio ambiente e melhora a vida das pessoas com quem interage" (SAVITZ \& WEBER, 2006).

Entretanto, há dificuldades para colocar em prática os conceitos associados ao desenvolvimento sustentável, em face da grandiosidade dos seus objetivos, os quais geram ceticismos diversos (FABER, et al, 2005), pois envolve uma série de questões éticas, morais 
e de valores individuais e coletivos, além de não favorecer os interesses das classes dominantes que em grande parte das vezes, somente visam ao lucro em suas operações.

A sustentabilidade é um assunto muito discutido e comentado em diversos meios, porém a realidade que permeia a situação ainda é bastante delicada. Pois na vida moderna, todos os setores da economia dependem de um fluxo constante de materiais, em um ciclo que começa na extração de matérias-primas naturais e segue em sucessivas etapas de transformações industriais, transporte, montagem, manutenção e desmontagem final (AGOPYAN \& JOHN, 2011, p.74).

O que talvez poucas pessoas levem em consideração, sendo de extrema importância, são as características do produto a ser adquirido, se o mesmo possui algum atestado que comprove o respeito ao meio ambiente, seu impacto ambiental na extração, na utilização e demolição, sua a durabilidade e reciclabilidade (ARAÚJO, 2013).

Ao se comprometer com o desenvolvimento sustentável, uma empresa deve necessariamente mudar sua forma de atuação, para no mínimo, reduzir os impactos sociais e ambientais adversos. Isso requer uma nova maneira de encarar a inovação, o que leva à ideia de inovação sustentável, ou seja, um tipo de inovação que contribua para o alcance do desenvolvimento sustentável (BARBIERI, 2010, p. 147).

O desenvolvimento pode ser entendido como o incremento positivo na satisfação das mais diversas necessidades do ser humano, como saúde, educação, habitação, transporte, alimentação, lazer, entre outras (OLIVEIRA, 2002). Já na visão de Sachs (1992), um novo estilo de vida deverá apresentar valores próprios, um conjunto de objetivos definidos socialmente e visão de futuro, no qual o desenvolvimento sustentável surge como um projeto de civilização.

Cabe salientar, que os institucionalistas entendem que as instituições servem para regulamentar o mercado e muitas vezes são necessárias para garantir que as empresas estejam atentas aos interesses dos atores sociais fora de si, principalmente hoje numa economia cada vez mais dinâmica e globalizada (SCOTT, 2003).

Deste modo, a sustentabilidade é uma forma de suprir as necessidades humanas através de medidas que minimizem impactos ambientais, ou que, ao menos, suas ações proporcionem menores prejuízos à natureza e aos grupos humanos. Entretanto, tal modo tem relações diretas com questões sociais, econômicas, culturais, éticas, valores morais individuais e organizacionais.

\subsection{Os dilemas da sustentabilidade}

Borger (2006) postula que as empresas estão paulatinamente percebendo que preservar a qualidade socioambiental pode ser uma oportunidade de investimento e de ganhos futuros, podendo se transformar numa vantagem competitiva, onde introduz vários 
conceitos e valores na gestão empresarial, os quais são decisivos para o sucesso dos negócios.

Todavia, vale destacar que a percepção do consumidor nem sempre é a mais correta (POLONSKI, 1994). Embora se admita que as organizações empresariais, em geral, devem assumir grande parte da responsabilidade relativa à degradação ambiental, são os consumidores que demandam os produtos criadores de problemas e são estes que decidem como e onde usar, e como e onde depositar o lixo.

Porém, a demanda por qualidade ambiental é elástica em relação à renda e ao nível educacional (REINHARDT, 1999), e gradativamente a própria pressão da sociedade forçará as organizações a se tornarem mais responsáveis em um futuro breve.

De certa maneira, espera-se que o compartilhamento de conhecimentos e o diálogo permitam reduzir o abismo entre a responsabilidade social empresarial, questões ambientais e as necessidades econômicas das organizações. Na ótica econômica, as decisões sobre o meio ambiente buscam reduzir riscos futuros e aproveitar as oportunidades para aumentar o valor agregado dos bens e serviços produzidos, o que coincide com o objetivo central de qualquer atividade empresarial: criar e capturar valores, reduzindo riscos e diminuindo os custos futuros.

Pedroso (2007) defende que a sustentabilidade corporativa pressupõe que as empresas apresentem resultados financeiros positivos, através da geração de valor e que sejam perenes através de uma efetiva gestão de riscos corporativos, para que se possam investir recursos na preservação do meio ambiente e no desenvolvimento social.

Por outro lado, faz-se necessária a criação de novos modelos de produção e estilos de vida nas condições e potencialidades ecológicas de cada região (LEFF, 2001). Vale destacar que os produtos da madeira concorrem em um mercado com ampla variedade de materiais substitutos, e de maneira geral, podem ser comparados uns aos outros no que se refere à análise do ciclo de vida, entre outras vantagens ambientais, isso dependerá de diversas situações, utilidades técnicas e preços, pois há demanda de mercado para uma ampla combinação de materiais e produtos para a construção civil (GONZAGA, 2005).

\subsection{O setor de industrialização da madeira no Brasil}

Desde os períodos mais antigos a utilização da madeira sempre esteve presente nas construções e na produção de utensílios para as mais diversas necessidades do homem, justificado pela facilidade do trabalho, grande variedade de espécies e, principalmente, pela abundância e capacidade de rápida renovação (GALVÃO \& JANKOWSKI, 1984). 
Assim, o consumo cada vez maior de materiais de construção, e as crescentes dificuldades para obtenção de madeira maciça, com dimensões e qualidade adequadas às diversas necessidades, juntamente com a explosão na tecnologia de fabricação ocorrida pouco antes da metade do século $X X$, conduziram o desenvolvimento das indústrias de produtos derivados de madeira (MORIKAWA, 2003). Este mercado vem se tornando cada vez mais promissor, inclusive no Brasil, onde grupos têm investido pesadamente na construção e modernização de gigantescas plantas industriais.

Ressalta-se que a indústria de madeira processada mecanicamente exerce uma forte influência na economia brasileira, tanto na geração de impostos como na geração de postos de trabalho e renda. Podendo-se afirmar que hoje o segmento tem um efeito multiplicador, sendo a base da cadeia produtiva de diversos produtos industriais manufaturados, que têm importância estratégica na economia de inúmeros países no mundo, incluindo o Brasil (MARTINI, 2003, p. 53).

$\mathrm{Na}$ esfera social, o setor madeireiro apresenta uma considerável empregabilidade, pois de acordo com dados recentes da Associação Brasileira da Indústria de Madeira Processada Mecanicamente - ABIMCI, no ano de 2016, o setor fechou com positiva variação nas vagas de trabalho em relação ao ano anterior. Com 57\% (369 mil) dos empregos da cadeia de base florestal brasileira, a indústria de madeira sólida que contempla produtos como painel de compensado, madeira serrada, pisos, portas e molduras, sendo responsável por 9\% do total de empregos formais do país, fechando em 2015 com 39,663 milhões de vagas de trabalho, segundo dados do Cadastro Geral de Empregados e Desempregados - CAGED.

Esse resultado, segundo a $\mathrm{ABIMCI}$ (2016), mostra a relevância do setor para a economia brasileira, mesmo diante de um período de desaceleração. Na esfera ambiental, o setor de produtos madeireiros apresenta benefícios e vantagens competitivas em relação a outros produtos substitutos (concreto, aço, plástico, entre outros). Ainda assim, é preciso contrapor-se à concorrência dos produtos substitutos, melhorar o desempenho da madeira com investimento em desenvolvimento tecnológico e de marketing, mesmo existindo a percepção popular que o uso da madeira está associado ao desmatamento descontrolado (GONZAGA, 2005).

$\mathrm{Na}$ comparação entre edificações similares construídas com estruturas de materiais diferentes (madeira, concreto e aço), pesquisas canadenses mostraram que as edificações em aço e concreto embutem de $26 \%$ a $57 \%$ mais energia; emitem de $34 \%$ a $81 \%$ mais gases de efeito estufa; liberam de $24 \%$ a $47 \%$ mais poluentes no ar; despejam de 4 a 3,5 vezes mais poluentes na água; usam de $11 \%$ a $81 \%$ mais matéria prima em peso; e produzem de $8 \%$ a $23 \%$ mais dejetos sólidos, respectivamente, do que as edificações em madeira (CWC, 2004). 
Com base nestes apontamentos, percebe-se que a madeira poderia vir a ser utilizada de forma muito mais adequada, possibilitando um desenvolvimento com vistas sustentáveis, quando comparada com outas matérias-primas. Entretanto, a falta de políticas públicas, incentivos aos manejos e o imediatismo pela obtenção do lucro, vêm sendo as principais consequências para a exploração descontrolada desse recurso natural, associando-se, muitas vezes, à exploração inadequada da mão de obra.

\subsection{A atividade madeireira nas regiões Sul Paranaense e Norte Catarinense}

Por muitos anos as atividades econômicas nas cidades que compõem as regiões Sul Paranaense e Norte Catarinense tinham origem basicamente no extrativismo, sendo a madeira o principal produto a ser explorado, e mais tarde, dando abertura para outras atividades. Hoje, mesmo não sendo a maior atividade geradora de emprego e renda, a industrialização de madeira ainda é considerada um dos grandes pilares de sustentação das economias locais. Com destaque para a de cidade de União da Vitória/PR conhecida no cenário nacional como a "Capital Nacional das Esquadrias de Madeira".

Roveda (2006), afirma que a exploração e a industrialização da madeira têm sido praticadas no município há mais de cem anos, destacando-se pela grande concentração de fábricas na região, gerando aproximadamente cinco mil empregos diretos, possibilitando o crescimento local e contribuindo para o desenvolvimento de novos segmentos.

No total são 255 estabelecimentos na região, sendo União da Vitória o município mais significativo da "APL da Madeira" em número de estabelecimentos (85). De acordo com a tipologia adotada pelo Projeto, o APL - Arranjo Produtivo Local, configura-se como um Núcleo de Desenvolvimento Setorial-Regional, ou seja, um sistema local com importância elevada para o setor madeireiro no Estado (IPARDES, 2006).

Ao lado de União da Vitória, encontra-se o município de Porto União/SC, o qual possui, entre outras finalidades, a mesma tradição no cultivo e processamento de madeira. Entre as atividades destaca-se o desdobramento da madeira, fabricação de madeira laminada e chapas de madeira compensada e a fabricação de esquadrias de madeiras e casas de madeira pré-fabricadas (BITTENCOURT \& OLIVEIRA, 2009).

\section{Métodos}

Essa pesquisa é caracterizada e se desdobra de acordo com os itens abaixo, sendo que os dados foram analisados a partir de abordagens quantitativa-subjetivas, a fim de se fazer compreender os dados levantados: 
a) Revisão bibliográfica, com a qual busca-se conhecer e analisar as contribuições culturais e científicas do passado, existentes sobre um assunto, tema ou problema (CERVO e BERVIAN, 1983, p. 55). Nesta fase, buscou-se utilizar referências fornecidas por professores do Programa de Pós-Graduação Interdisciplinar em Desenvolvimento Comunitário, especialmente direcionadas à Gestão Sustentável, associada à demais bibliografias conhecidas no espaço acadêmico.

b) Pesquisa exploratória, que tem como objetivo proporcionar maior familiaridade com o problema, visando torna-lo mais explícito ou mesmo construir hipóteses (GIL, 2002, p. 41). Nessa fase e a partir de levantamentos prévios, desenvolveu-se um instrumento de pesquisa (questionário), o qual proporcionou um direcionamento para entrevistas de campo, com a finalidade de levantar informações que à frente serão demonstradas e analisadas, com vista a fazer conhecer os avanços obtidos por uma empresa, que a partir de resíduos industriais de madeira, reprocessa e os fornece como nova matéria prima à manufatura de portas e compensados de madeira.

c) Estudo de caso, o qual torna-se importante no sentido de buscar aprofundamento e compreender fenômenos sociais complexos, dando a oportunidade para que o aspecto de um problema seja explanado (BELL, 1989, p. 145). Nessa fase, buscou-se através do diálogo com os principais atores, perceber os benefícios e desafios de suas atividades, bem como apresentar os avanço e limitações que o caso discutido a seguir pode expor.

\section{Análise e discussão dos resultados}

\section{1. $O$ caso da SPS Tecnologia Ambiental Ltda.}

$\mathrm{Na}$ avaliação de campo, foi possível apontar um caso, já de prévio conhecimento dos autores deste artigo, o qual apresenta um relato a partir de uma entrevista estruturada aos idealizadores da SPS Tecnologia Ambiental Ltda. (http://www.spsambiental.eco.br), empresa que possui sua planta industrial localizada no município de Porto União/SC, sendo especializada no gerenciamento de resíduos sólidos provenientes do setor madeireiro, mais especificamente de fábricas de portas e chapas compensadas, abundantes em sua região, objetivando eliminar as agressões ambientais causadas pelos resíduos destes produtos, tendo como premissa o desenvolvimento sustentável.

Sua fundação deu-se em 2005, e segundo seus idealizadores, é a única empresa na América Latina considerada como destinação final ambientalmente adequada, pois além do recolhimento, executa ações de reciclagem, produzindo a partir destes resíduos novos produtos adesivos, evitando destinar dejetos a aterros industriais. Assim, a empresa desenvolve pesquisas e processamento de materiais, apresentando um novo conceito: o processamento e recuperação de resíduos considerados altamente poluentes e prejudiciais 
à saúde humana, em subprodutos (extensores e resinas) que serão reutilizados nos processos produtivos dos próprios parceiros fornecedores dos rejeitos.

Entre as vantagens, caracterizam-se através dos serviços ambientais a reciclagem, diminuindo os riscos de danos ambientais, como a poluição de corpos hídricos, do solo ou da atmosfera, entre outros prejuízos à sociedade. Assim a empresa defende os conceitos estipulados pela Política Nacional de Resíduos Sólidos (instituídos pela Lei no 12.305 de 02 de agosto de 2010), que proíbe as destinações de resíduos sólidos através de lançamento em corpos hídricos, em céu aberto, por meio da queima ou outras formas vedadas por órgãos ambientais.

A SPS Tecnologia Ambiental (Figura 01) possui o licenciamento ambiental registrado (sob no IND47039CPN) no Instituto Brasileiro do Meio Ambiente - IBAMA, o qual representa o conjunto da legislação brasileira de proteção ao meio ambiente, um dos instrumentos mais importantes para conduzir a sociedade à prática ambientalmente correta. Este licenciamento ambiental ocorre no âmbito estadual, mas pode ser efetivado também no âmbito federal.

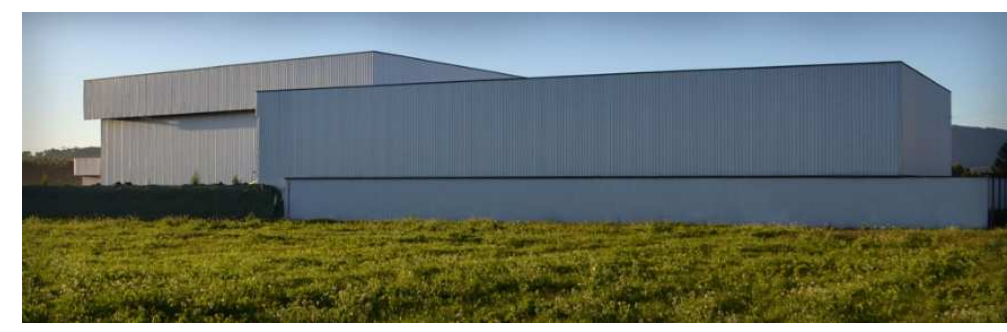

Figura 1 - Vista externa das instalações industriais

Fonte: http://www.spsambiental.eco.br/quemsomos/ (2018)

Em relação à operacionalidade e logística dos resíduos, a empresa fornece aos seus clientes/parceiros, embalagens exclusivas para a destinação de Resíduos Classe I (resinas fenólica, formol-aldeído) oferecendo ainda suporte técnico tanto na coleta, quanto na utilização de seus produtos, bem como possui e atesta evidências na economia de produção, sendo que comprovações práticas apontam a possibilidade de utilização em torno de 15 a 30\% do produto SPS Neo Action F, na substituição da resina na preparação da cola para madeira (adesivo a base de resina, farinha de trigo, água e catalizador) utilizado nas indústrias de portas e chapas de compensado. Entretanto, apenas um cliente utiliza tal produto a mais de cinco anos, atestando sua eficiência (Formare Ind e Com de Compensados Ltda).

A ideia de reutilizar rejeitos (resinas e outros químicos) basicamente, surgiu a partir de um pedido de uma indústria que solicitou pesquisas e o desenvolvimento de produtos a partir de sobra/resíduos industriais, os quais possuíam ainda propriedades adesivas, porém 
não estava mais no estado líquido ou mesmo particulado (pó), assim foram surgindo experiências que reativassem o material quimicamente, chegando a um resultado satisfatório, pois até então o destino final era aterros industriais em quantidades limitadas, causando custos para sua retirada, ou mesmo outros fins clandestinos e inadequados.

Entre as dificuldades iniciais, pode-se afirmar que o fato de não existir algo igual, ou mesmo parecido, fez com que os órgãos ambientais e mesmo o Instituto Nacional da Propriedade Industrial - INPI, não entendessem o que de fato pretendia-se fazer, acarretando em alta burocracia, inclusive maior que na própria fonte produtora do resíduo. Além disso, a questão cultural ainda é tida como uma das principais barreiras, tendo em vista que há resistência/descrença por parte dos stakeholders (empresários, colaboradores e consumidores) locais em aceitar a necessidade de buscar soluções aos passivos ambientais, bem como acarretar com os dispêndios financeiros. O que faz a direção da SPS Tecnologia Ambiental Ltda. perceber que tais medidas são incorporadas somente em longo prazo.

Entre as vantagens, aponta-se a criação de uma simbiose na região, na qual o resíduo de uma empresa pode, a partir de um reprocessamento, tornar-se matéria prima para outra empresa, favorecendo a reutilização de materiais até então destinados ao descarte, inclusive comercializados a preços mais competitivos, como é o caso do óleo vegetal (de cozinha) usado, que transforma-se em óleo desmoldante para equipamentos, diminuindo o atrito entre o material e a máquina, sem causar marcas ou manchas na madeira.

Entre as exigências dos clientes, uma das características fundamentais é a padronização dos produtos, o qual uma vez ajustado aos processos, a SPS Tecnologia Ambiental Ltda. possui um rígido controle de qualidade, o que se refere à uniformidade de seus produtos, algo que nem sempre os resíduos recebidos possuem em virtude das mais diversas formas de processamento (batidas de cola). E, claro, condições associadas a um preço competitivo.

A capacidade produtiva da planta industrial pode chegar à 10 toneladas/dia, devido ao dimensionamento de seus reatores. Entretanto pelas dificuldades de colocação de seus produtos, a empresa vem desenvolvendo uma nova linha de fabricação destinados a coating (revestimentos) e mesmo fabricação de tintas e vernizes, uma vez que possui instalações fabris adequadas e um considerável conhecimento sobre o assunto. Por outro lado, há intensões de novos investimentos no que tange às soluções ambientais, porém a região não dispõe de volume suficiente de resíduos, o que de momento inviabiliza este tipo de investimentos.

No aspecto social, a empresa oferta sete postos de trabalho, entre laboratoriais, operacionais e equipe técnica-comercial, bem como produz renda local e arrecadação de impostos, por um lado existe todo um considerável investimento em estruturas e 
conhecimentos práticos, no qual ainda enfrentam barreiras classificadas pelos atores como pré-conceitos. Já no questionamento ao desenvolvimento de novos produtos, os idealizadores informam que vêm desenvolvendo matérias primas para indústria madeireira (cola branca - PVA), químicos para indústria de papel e mesmo matérias para a construção civil.

No questionamento aberto quanto às expectativas de futuro, há duas respostas, onde de um lado percebe-se certa angústia em não obter uma plena valorização das soluções desenvolvidas, e de outro o fato de poder salientar os benefícios como a reutilização de mais de 600 toneladas de resíduos industriais, que na melhor das hipóteses, poderia estar em aterros industriais e mesmo a reutilização de mais de 10 mil baldes (embalagens) de plástico na produção de tintas, que ainda está em fase inicial.

\section{Considerações finais}

O presente artigo, de forma breve procurou resgatar parte das discussões atuais sobre desenvolvimento sustentável, associando ao caso da SPS Tecnologia Ambiental Ltda., empresa que vem alterando de forma prática e responsável a destinação de resíduos industriais, especialmente de considerados de grande impacto à saúde humana.

O fato da fábrica não estar totalmente finalizada, tem relação com o Risco Brasil, e às incertezas no atual cenário político e econômico, o que vem causando instabilidade no setor produtivo, assim como a falta de investimentos em pesquisa e desenvolvimento, no contexto brasileiro, pois houve diversas outras experiências, entre elas a possibilidade de desenvolver produtos tal como o enchimento (recheio) de portas, entretanto o nível de investimento está muito além da realidade presente.

Entre as conclusões, aponta-se que o pré-conceito ao uso dos produtos gerados pela SPS Tecnologia Ambiental Ltda., como questões de ordem cultural, o imediatismo aliado às necessidades de ganhos rápidos como questões de ordem econômica e as falhas nas políticas ambientais ineficazes do ponto de vista prático, são os principais desafios enfrentados por esta organização, que vem adotando em paralelo a criando uma nova linha de produtos na intenção de aproveitar sua atual estrutura.

Salienta-se que indiferente do tamanho, cedo ou tarde haverá a necessidade de as empresas locais começarem a tomar iniciativas por ações mais sustentáveis, seja pelo fato de serem cobradas pela legislação, ou mesmo pelo fato de sentirem as exigências de seus clientes, influenciados pelas mídias, ONGs, entre outros movimentos, ou por uma necessidade de procurarem diferenciais visando atingir públicos mais específicos (REINHARDT, 1999). 
Ainda como contribuição, aponta-se com uma alternativa às práticas sustentáveis a certificação de produtos madeireiros oriundos de florestas manejadas ou mesmo certificadas, pois diminuem em grandes proporções os passivos ambientais, sendo considerado uma ferramenta de mercado que atesta se uma empresa ou comunidade maneja suas florestas de acordo com padrões (regras) pré-definidos e acordados entre os diversos setores da sociedade, garantindo a legalidade e utilização racional, porque requerem um cumprimento de normas que vão além da legalidade.

E, também, um maior interesse das empresas locais a procurarem desenvolver estudos e ações no que se refere à responsabilidade social empresarial, pois com tais medidas, melhora-se a imagem organizacional, proporciona uma maior satisfação dos stakeholders e a comunidade entende de maneira mais consciente o grau de importância da organização no seu entorno.

\section{REFERÊNCIAS}

ABIMCI. Geração de emprego mostra importância da indústria da madeira para a economia. Disponível em <http://www.abimci.com.br/geracao-de-emprego-mostraimportancia-da-industria-da-madeira-para-a-economia/> Acesso em: 09 dez.2016.

AGOPYAN, V. e JOHN, V. M. Desafio da Sustentabilidade na Construção Civil. São Paulo: Blucher, 2011.

ARAÚJO, R. T. Alternativas sustentáveis de uso da madeira na construção civil. Especialize - IPOG janeiro/2013.

BARBIERI, J. C. Inovação e sustentabilidade: Novos modelos e proposições. RAE, São Paulo v. 50, n. 2, abr./jun. 2010, 146-154 ISSN 0034-7590.

BELL, J. Doing your research project: a guide for the first-time researchers in education and social science. 2. reimp. Milton Keynes. England: Open University Press. 1989. pp. 145.

BITTENCOURT, L. P., OLIVEIRA, G. B. A indústria madeireira paranaense nos anos recentes. Revista das Faculdades Santa Cruz, v. 7, n. 1, janeiro/junho 2009.

BORGES, F. G. Responsabilidade Corporativa: a dimensão ética, social e ambiental na gestão das organizações. In: JÚNIOR, A. V; DEMAJOROVIC, J. (Org.). Modelos e Ferramentas de Gestão Ambiental: desafios e perspectivas para as organizações. São Paulo: Editora Senac, 2006.

CANADIAN WOOD COUNCIL. Energy and the environment in residential construction 2004. Sustainable Building Series. N.1. Disponível em: <http://cwc.ca/wpcontent/uploads/publications-Energy-and-the-Environment.pdf> Acesso em: 20 dez. 2016.

CERVO, A. L; BERVAIN, P. A. Metodologia cientifica: para uso dos estudantes universitários. McGraw-Hill do Brasil. São Paulo, 1983. 
CNUMAH. Declaração de Estocolmo sobre o ambiente humano. Estocolmo, 1972. Disponível em: Acesso em: 06 dez.2016 $<$ http://www.educacaoambiental.pro.br/victor/unidades/DeclaraAmbienteHumano.pdf ELKINGTON, J. Canibais com garfo e faca. São Paulo: Makron Books, 2001.

FAO. Forestry Department country profiles. Disponível em: http://www.fao.org/forestry. Acesso em: 10 dez.2016.

FABER, N; JORNA, R; ENGELEN, J. The sustainability of sustainability: a study into the conceptual foundations of the notion of "sustainability". Journal of Environmental Assessment Policy and Management, v. 7, n. 1, p. 1-33, mar. 2005.

LEFF, E. Saber Ambiental: sustentabilidade, racionalidade, complexidade, poder. 2. ed. RJ: Vozes, 2001. Tradução de Lúcia Mathilde Endlich Orth

GALVÃO, A. P. M. e JANKOWSKI, I. P. Secagem racional da madeira. Livraria Nobel S. A. São Paulo: 1984.

GONZAGA, C. A. M. Marketing verde de produtos florestais: teoria e prática. Floresta, Curitiba, PR, v. 35, n. 2, mai/ago. 2005.

GIL, A. C. Como Elaborar Projetos de Pesquisa. 4ํe․ São Paulo: Atlas, 2002.

MARTINI, S. A competitividade da micro e pequena empresa madeireira na região do Vale do Iguaçu: suas potencialidades e fragilidades. Florianópolis: Dissertação de mestrado do Departamento de Economia da Universidade Federal de Santa Catarina, 2003. MORIKAWA, M. S. Materiais alternativos utilizados em formas para concreto armado. USP. Campinas, 2003.

OLIVEIRA, G. B. Uma discussão sobre o conceito de desenvolvimento. Revista da FAE, Curitiba, v.5, n.2, p.41-48, maio/ago. 2002.

PEDROSO, M. C. Casos Sustentáveis. FGV-EAESP, v.6, n. 2, março-abril/2007. Disponível em <www.rae.com.br/executivo> Acesso em: 14 de setembro de 2009.

POLONSKY, M. J. An introduction to green marketing. In: Electronic Green Journal, ISSN: 1076-7975, v. $1, \quad$ n. $2, \quad$ nov/1994. Disponível em: <http:gopher.uidaho.edu/1/Ul_gopher/library/egj>. Acesso em: 8 out.2003.

REINHARDT, F. L. Down to earth: applying business principles to environmental management. Boston: Harvard, 1999.

ROVEDA, C. Uma história ligada à indústria madeireira. Suprimento Especial do Jornal 0 Estado do Paraná. Curitiba, 22 de Outubro de 2006.

SACHS, W. Esplêndido fracasso. Comunicações do ISER. 44. Rio de Janeiro: ISER, 1992. SAVITZ, A. W.; WEBER, K. The triple bottom line: how today's best-run companies are achieving economic, social and environmental success and how you can too. San Francisco: John Willey \&Sons, 2006. 
SCOTT, W. R. Organizations: Rational, natural and open systems. $5^{\circ}$ ed. Upper Saddle River, NJ: Prentice-Hall, 2003.

SPS Tecnologia Ambiental. Disponível em <http://www.spsambiental.eco.br> Acesso em: 24 de set. de 2018.

WORLD BANK. World development report, 1992. New York: World Bank and Oxford University Press, 1992.

Arranjo Produtivo Local da Madeira de Porto União da Vitória: Nota Técnica.

IPARDES-Curitiba, 2006. Acesso em: 22 dez. 2016. Disponível em: <http://www.ipardes.gov.br/biblioteca/docs/apl_madeira_esquadria_uniao_vitoria.pdf> 